\title{
Relative Endowments and the Volume of Trade
}

\author{
Kwok Tong Soo \\ Lancaster University
}

\begin{abstract}
This paper provides evidence that the volume of trade may increase as countries' relative endowments become more similar. A model is developed that can explain this phenomenon. The model is a four-good version of the Davis (1995) Heckscher-Ohlin-Ricardo model of international trade based on technological and factor endowment differences across countries. In the model, trade volumes may increase with greater similarity in relative endowments, because productivity differences across countries mean that countries' production becomes increasingly specialised the more similar are their relative endowments.
\end{abstract}

- JEL Classification: F11

- Key Words: international trade, trade volume, integrated equilibrium

\section{Introduction}

This paper proposes an explanation for the large trade volumes observed between countries that are similar to one another in terms of their relative factor endowments. The most obvious example of this phenomenon is the relatively similar countries of the European Union trading largely amongst themselves. This case may be at least partly explained by the proximity of the countries to one another, which suggests some gravity-type explanation such as that proposed by Anderson (1979) or more recently by the New Economic Geography literature (see Fujita, Krugman and Venables (1999)). However, there are other examples as well where the trade volume between two countries that are similar in terms of their

\footnotetext{
*Kwok Tong Soo: Department of Economics, Lancaster University Management School, Lancaster, LA1 4YX, United Kingdom, Tel: +44 (0) 1524594418, e-mail: k.soo@lancaster.ac.uk.

(C2009-Center for International Economics, Sejong Institution, Sejong University, All Rights Reserved.
} 
economic structure, is larger than the trade volume between two countries that are very different from one another. For example, consider US trade in goods and services with Switzerland and Indonesia. The Swiss and the Indonesian economies are approximately the same size (measured in nominal exchange rates), and the value of their trade with the rest of the world is also similar to one another. It may be said that the Swiss economy is more similar to the US economy than is the Indonesian economy, in terms of relative endowments. However, trade between Switzerland and the US is larger than trade between the US and Indonesia (\$32 billion for Switzerland and $\$ 19$ billion for Indonesia in 2007; figures from the World Trade Organisation). More formal econometric evidence as presented in section 2 also confirms the complex relationship between relative factor endowments and the volume of trade.

Such trade patterns pose a problem for standard models of international trade. The theory of international trade based on comparative advantage suggests that countries should trade more with trading partners which are more different from themselves; the new trade theory based on increasing returns allows for the possibility of trade between countries which are identical in terms of their technologies, endowments, and preferences, but at least in the standard development of the model by Helpman and Krugman (1985), the volume of trade never increases the more similar are countries from one another in terms of their relative endowments.

The explanation proposed in this paper is based on the idea that countries may differ from one another in terms of both their relative endowments and in the level of technology used in production. As a result of these different levels of technology, countries may become more specialised in production even as they become more similar in their relative endowments. It is this increased specialisation that may lead to greater volumes of trade between more similar countries. In particular, we find a nonlinear relationship between trade volumes and similarity in relative endowments, with trade volumes at first decreasing, then increasing as countries become more similar to one another. That countries are specialised in different goods as a result of differences in technologies and factor endowments is consistent with the empirical evidence from Harrigan (1997).

This paper provides an alternative to the explanation that is usually proposed for this phenomenon of countries trading more with trading partners that are more similar to themselves. The usual approach is to introduce nonhomothetic preferences into a model of international trade. Nonhomothetic preferences would 
imply that capital-abundant countries have higher per-capita incomes and may therefore demand more of the goods produced by other capital-abundant countries, thus generating larger volumes of trade between countries with similar relative endowments. This line of thought has a long tradition, starting from Linder (1961), and through Markusen (1986), Flam and Helpman (1987), Stokey (1991), Matsuyama (2000), Ramezzana (2002), Chung (2003) and Mitra and Trindade (2005). What the present paper shows is that nonhomothetic preferences are not necessary to generate large trade volumes between countries with similar relative endowments.

The model in this paper is an extension of Davis's (1995) Heckscher-OhlinRicardo model of international trade based on technological and factor endowment differences across countries. Our model is able to generate larger trade volumes between more similar countries in a comparative advantage framework. This is similar to the finding in Davis (1997); however the structure of the model in that paper is quite different from that in the present paper. In Davis (1997) it is differences in the factor intensities across industries and within industries that determine the volume of trade between different groups of countries. ${ }^{1}$ Also related to the present paper is Balboni (2006), who adapts the Heckscher-Ohlin-Ricardo model to explain vertical intra-industry trade in a three-good framework.

Section II provides some stylised facts on the relationship between trade volume and relative factor endowments. Section III develops the model, then analyses the characteristics of the integrated equilibrium. Section IV analyses the trade patterns and trade volumes that arise in the model, and the final section provides some concluding comments.

\section{Stylised Facts}

This section provides some stylised facts on the relationship between relative endowments and the volume of trade. We estimate the following model:

\footnotetext{
${ }^{1}$ To be precise, in Davis (1997), there are identical technologies, four countries, two in the North, and two in the South, four factors of production, and four goods, with two goods being intensive in factors with which the North countries are abundant, and the other two goods being intensive in factors with which the South countries are abundant. Davis (1997) shows that the two countries in the North can have large trade volumes between themselves if the two North goods are technologically very similar to each other, since in this case, any given difference in relative endowments requires a larger volume of trade to satisfy the net factor content of trade. Because of the assumption of identical technologies, in Davis (1997) if two countries have identical relative endowments they will not trade with each other; however, in the model we develop, countries with identical relative endowments can still trade with each other.
} 


$$
\text { Trade Share } \text { S }_{t}=\beta_{0}+\beta_{1} t+\beta_{2} C V G D P_{t}+\beta_{3} C V\left(\frac{K}{L}\right)_{t}+\varepsilon_{t}
$$

Trade share is the share of exports and imports in world GDP; $t$ is a time trend capturing the increased share of trade in world GDP over time. $C V G D P$ is the coefficient of variation (standard deviation divided by the mean) of GDP across all countries in the world, and $C V(K / L)$ is the coefficient of variation of the capital stock per person across all countries; capital stock is calculated using the perpetual inventory method from investment data. ${ }^{2}$ Equation (1) estimates the world trade volume as a function of the difference in country sizes and the difference in relative factor endowments.

Table 1. Trade Shares, GDP and Capital-labour Ratios

\begin{tabular}{ccccc}
\hline & \multicolumn{2}{c}{ Dependent variable: Share of international trade in world GDP } \\
& \multicolumn{2}{c}{ All countries } & \multicolumn{2}{c}{ Consistent sample } \\
& $(1)$ & $(2)$ & $(3)$ & $(4)$ \\
\hline Year & 0.673 & 0.665 & 0.452 & 0.493 \\
& $(24.73)^{* * *}$ & $(29.54)^{* * *}$ & $(12.78)^{* * *}$ & $(9.42)^{* * *}$ \\
CV GDP & -2.585 & -89.319 & 6.277 & -175.063 \\
& $(1.66)^{*}$ & $(1.69)^{*}$ & $(0.72)$ & $(1.93)^{*}$ \\
$(\mathrm{CV} \text { GDP })^{2}$ & & 13.301 & & 36.945 \\
& & $(1.63)$ & & $(2.31)^{* *}$ \\
CV $(\mathrm{K} / \mathrm{L})$ & 18.452 & -501.752 & 3.565 & -379.207 \\
& $(1.43)$ & $(4.29)^{* * *}$ & $(0.14)$ & $(2.30)^{* *}$ \\
$(\mathrm{CV}(\mathrm{K} / \mathrm{L}))^{2}$ & & 264.992 & & 182.671 \\
& & $(4.52)^{* * *}$ & & $(2.29)^{* *}$ \\
Constant & $-1,303.990$ & -894.195 & -883.353 & -544.902 \\
& $(21.21)^{* * *}$ & $(7.43)^{* * *}$ & $(11.65)^{* * *}$ & $(3.68)^{* * *}$ \\
\hline Observations & 54 & 54 & 54 & 54 \\
Centered $R^{2}$ & 0.93 & 0.94 & 0.88 & 0.92 \\
AR(1) test $z$-stat & 1.00 & 1.00 & 1.00 & 1.00 \\
AR(1) test $p$-value & 0.32 & 0.32 & 0.32 & 0.32 \\
\hline Na* signicant at $10 \% ; * *$ & & & \\
\hline
\end{tabular}

Notes:* significant at 10\%; ** significant at 5\%; $* * *$ significant at $1 \%$. Estimation method is GMM with heteroskedasticity and autocorrelation consistent (HAC) z-statistics in parentheses. CV GDP is the coefficient of variation of GDP across countries. $\mathrm{CV}(\mathrm{K} / \mathrm{L})$ is the coefficient of variation of capital stock per capita across countries. The AR(1) test is the Arellano and Bond (1991) test for serial correlation in the residuals. See Baum et al. (2007) for details of the estimation method.

\footnotetext{
${ }^{2}$ To be precise, we estimate the initial capital stock in 1950 as $\mathrm{I} 50 /(\mathrm{g}+\mathrm{d})$ where I50 is the investment in $1950, \mathrm{~g}$ is the average growth rate of investment from 1950 to 1960 , and $\mathrm{d}$ is the depreciation rate which is assumed to be 6 percent.
} 
Data for all variables in current prices are obtained from the Penn World Tables 6.2 from 1950 to 2003 (Heston, Summers and Aten (2006)). Since the variables are world values, we have only one observation for each year. As a result, the error term may well be serially correlated. We therefore estimate the model using GMM, and report heteroskedasticity and autocorrelation robust (HAC) standard errors. We also report the results of the Arellano and Bond (1991) test for serial correlation in the residuals (see Roodman (2009)).

The results for regression (1) are reported in columns (1) and (3) of Table 1. Column (1) includes all available countries in the Penn World Tables (the full sample). The number of countries increases over time. Column (3) includes only the countries that have always been in the Penn World Tables (the consistent

Figure 1. Scatterplots of Residuals against the Coefficient of Variation in GDP and K/L from Equation (1)

Figure 1(a): Residuals against GDP plot, full sample

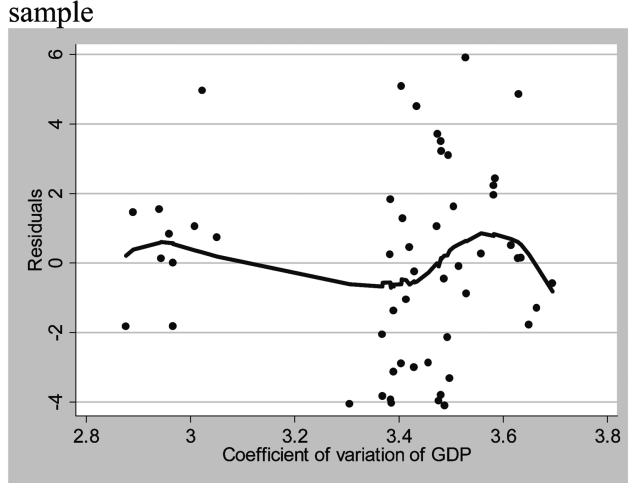

Figure 1(c): Residuals against GDP Plot, Consistent Sample

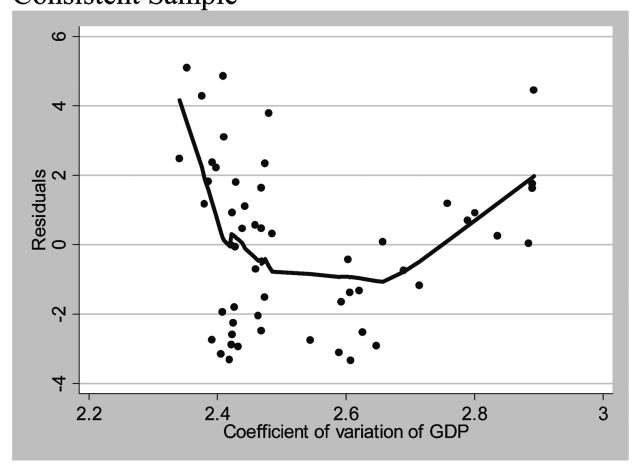

Figure 1(b): Residuals against (K/L) plot, full sample

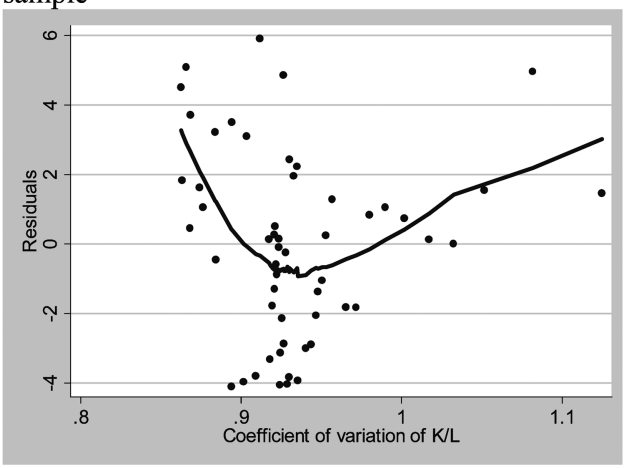

Figure 1(d): Residuals against (K/L) Plot, Consistent Sample

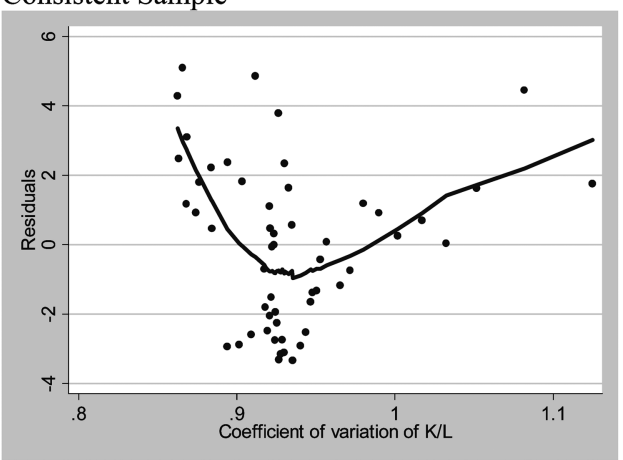

Note: The curves are the lowess smooths of the scatterplots. 
sample). This reduces the number of countries used to 51 countries. The results using either sample are similar to each other: only the coefficient of variation in GDP is significantly and negatively related to trade as a share of world GDP, and only in the full sample at 10 percent significance. Capital per worker does not have a significant impact on trade share using either sample. The Arellano and Bond test detects no evidence of serial correlation in the residuals.

Figures 1(a) to 1(d) report the scatterplots of the residuals from the regressions of equation (1) against the coefficient of variation in GDP and capital per worker for both samples, and a lowess smooth of the plotted points to help detect nonlinearity. There is evidence of a nonlinear relationship between the residual and the coefficient of variation of both GDP and capital per worker. For both variables, as the coefficient of variation increases (that is, as countries become on average more different from the mean) the residual first decreases, then increases. This indicates that a quadratic relationship between the trade share and the two variables would be preferred to the linear relationship estimated in equation (1). We therefore estimate the following model:

$$
\begin{gathered}
\text { Trade Share } \text { S }=\beta_{0}+\beta_{1} t+\beta_{2} C V G D P_{t}+\beta_{3}(C V G D P t)^{2} \\
+\beta_{4} C V\left(\frac{K}{L}\right)_{t}+\beta_{5}\left(C V\left(\frac{K}{L}\right)\right)_{t}^{2}+\varepsilon_{t}
\end{gathered}
$$

The results of estimating equation (2) are reported in columns (2) and (4) of Table 1 for the full and consistent samples of countries, respectively. The inclusion of the quadratic terms allows us to check for possible nonlinear relationships between the variables. In both samples we find strong evidence of a quadratic, Ushaped relationship between trade share and the coefficient of variation in capital per worker, consistent with Figure 1. We also find evidence of a quadratic, Ushaped relationship between trade share and the coefficient of variation in GDP for the consistent sample of countries in column (4).

To summarise, our stylised facts suggest that there is a U-shaped relationship between trade as a share of world GDP and the coefficient of variation of capital stock per worker, and the coefficient of variation of GDP. That is, greater dissimilarity in relative endowments or relative country sizes first decreases, then increases the volume of trade. The rest of this paper develops a model that is consistent with both nonlinear relationships, with a particular emphasis on the relationship between trade shares and relative endowments. 


\section{The Model}

We develop a model with factor endowment and technological differences across countries. There are two countries, $j=H, F$ (Home and Foreign), and four goods in two pairs, $i \in\left\{X_{1}, X_{2}, Y_{1}, Y_{2}\right\}$. Each product is produced using capital $K$ and labour $L$ using a constant-returns-to-scale production function, with goods in each pair having the same factor intensities, and the X-goods being capitalintensive relative to the Y-goods at any factor price ratio: $\left(\frac{K}{L}\right)_{X}>\left(\frac{K}{L}\right)_{Y}$. Both countries are equally productive in goods $X_{2}$ and $Y_{2}$, whilst there are Hicks-neutral technological differences across countries in goods $X_{1}$ and $Y_{l}$, so that the production functions take the form:

Home: $\quad Q_{X_{1}}^{H}=\left(A_{X}^{H} F\left(K_{X_{1}}^{H}, L_{X_{1}}^{H}\right)\right) \quad Q_{X_{2}}^{H}=\left(F\left(K_{X_{2}}^{H}, L_{X_{2}}^{H}\right)\right)$

$$
Q_{Y_{1}}^{H}=\left(A_{Y}^{H} G\left(K_{Y_{1}}^{H}, L_{Y_{1}}^{H}\right)\right) \quad Q_{Y_{2}}^{H}=\left(G\left(K_{Y_{2}}^{H}, L_{Y_{2}}^{H}\right)\right)
$$

Foreign: $\quad Q_{X_{1}}^{F}=\left(A_{X}^{F} F\left(K_{X_{1}}^{F}, L_{X_{1}}^{F}\right)\right) \quad Q_{X_{2}}^{F}=\left(F\left(K_{X_{2}}^{F}, L_{X_{2}}^{F}\right)\right)$

$$
Q_{Y_{1}}^{F}=\left(A_{Y}^{F} G\left(K_{Y_{1}}^{F}, L_{Y_{1}}^{F}\right)\right) \quad Q_{Y_{2}}^{F}=\left(G\left(K_{Y_{2}}^{F}, L_{Y_{2}}^{F}\right)\right)
$$

where $Q_{i}^{j}$ indicates production of good $i$ in country $j$. For example, the capitalintensive goods $X_{1}$ and $X_{2}$ may be the steel industry, where the identical-technology good $X_{2}$ represents generic goods such as nuts and bolts, whereas the technologically differentiated good $X_{I}$ represents advanced alloys which require expertise which exists only in some countries but not in others. Similarly, the labour-intensive goods $Y_{1}$ and $Y_{2}$ may be the textile industry, where $Y_{2}$ represents goods such as t-shirts, while good $Y_{l}$ represents goods such as new fabrics with special properties.

Factors of production are perfectly mobile across sectors within each country, but immobile across countries. All markets are perfectly competitive. We assume that the Hicks-neutral technology parameters $A_{i}^{j} \geq 1$, although this is not crucial for what follows. Davis's (1995) setup is simply the one above with the additional constraint that $A_{Y}^{F}=A_{X}^{F}=A_{Y}^{F}=1$.

Consumer utility is assumed to be identical across countries, and takes a CobbDouglas form: 


$$
U=\Sigma\left(\alpha_{i} \log \mathrm{c}_{i}\right) \quad \sum \alpha_{i}=1
$$

so that the consumer spends a share $\alpha_{i}$ of his income on each of the four goods.

\section{A. Integrated Equilibrium}

In deriving the volume of trade in our model, we make use of the integrated equilibrium approach. We develop new results on the size of the integrated equilibrium in the Heckscher-Ohlin-Ricardo model relative to the Heckscher-Ohlin model that will aid us in our analysis. Following Davis (1995), we ask: what divisions of the world endowment of capital and labour are consistent with replicating the integrated equilibrium, that is, the resource allocation that would occur if both goods and factors of production are freely traded. In the integrated equilibrium factor price equalisation (FPE) holds across countries.

To replicate the integrated equilibrium, it must be the case that each country produces the world output of the good(s) in which it has an absolute technological advantage. This is true irrespective of whether the technological difference between countries is small or large. Given the constant expenditure share on each good imposed by the Cobb-Douglas utility function, we have Proposition 1:

Proposition 1: In the integrated equilibrium, the ratio of the factors of production used in producing $X_{1}$ to that used in producing $X_{2}$ is equal to the relative expenditure shares on the $X$-goods, $\frac{\alpha_{X_{1}}}{\alpha_{X_{2}}}$, and the ratio of the factors of production used in producing $Y_{1}$ to that used in producing $Y_{2}$ is equal to the relative expenditure shares on the Y-goods, $\frac{\alpha_{Y_{1}}}{\alpha_{Y_{2}}}$.

Proof: We show the proof for the X-goods; the proof for the Y-goods is analogous. In the integrated equilibrium, the country that has the technological advantage in producing $X_{1}$, will produce the world output of $X_{1}$. In equilibrium, the ratio of the expenditure shares must be equal to the ratio of the total worldwide revenues of each industry, so that $\frac{\alpha_{X_{1}}}{\alpha_{X_{2}}}=\frac{p_{X_{1}} A_{X}^{j *} F\left(K_{X_{1}}^{W} L_{X_{1}}^{W}\right)}{p_{X_{2}} F\left(K_{X_{2}}^{W}, L_{X_{2}}^{W}\right)}$, where $A_{X}^{j *}$ is the Hicksneutral technology parameter for the country that has the technological advantage in $X_{I}$, and $K_{X_{I}}^{W}$ is the total capital used in producing $X_{I}$ in the world. But in the integrated equilibrium, since the country with the technological advantage in $X_{1}$ at least potentially produces both goods $X_{1}$ and $X_{2}$, it must be the case that the relative price of goods $X_{1}$ and $X_{2}$ is equal to the opportunity cost of production in this country: $\frac{p_{X_{1}}}{p_{X_{2}}}=\frac{1}{A_{X}^{j *}}$. Therefore, $\frac{\alpha_{X_{1}}}{\alpha_{X_{2}}}=\frac{F\left(K_{X_{1}}^{W}, L_{X_{1}}^{W}\right)}{F\left(K_{X_{2}}^{W}, L_{X_{2}}^{W}\right)}=\frac{K_{X_{1}}^{W}}{K_{X_{2}}^{W}}=\frac{L_{X_{1}}^{W}}{L_{X_{2}}^{W}}$, where the third 
equality comes from the fact that, in the integrated equilibrium, the capital-labour ratio of $X_{1}$ and $X_{2}$ are identical, and the second equality comes from the previous fact, and from our assumption of constant returns to scale.

Proposition 1 shows that it is the relative weights placed by consumers on the technologically-differentiated versus the technologically identical goods within each industry pair that determines the dimensions of the integrated equilibrium. A greater weight placed on the technologically differentiated good reduces the size of the integrated equilibrium. This is because to replicate the integrated equilibrium, countries with a technological advantage in producing a good must produce the world output of that good. The greater the weight that consumers place on these goods, the greater the resources required to produce the world output of these goods, hence the more restricted is the possible allocation of resources that can replicate the integrated equilibrium. Notice also that the proof of Proposition 1 implies that the allocation of resources between the two X-industries is independent of the relative (and absolute) level of technology in each X-industry, and is also independent of the relative demand for the Y-industries.

Suppose for concreteness that $A_{X}^{H}>A_{X}^{F}$ and $A_{Y}^{F}>A_{Y}^{H}$, so that Home has an absolute (and comparative) technological advantage in producing good $X_{l}$, while Foreign has an absolute and comparative technological advantage in producing good $Y_{1}$. Therefore, to replicate the integrated equilibrium, Home must produce the world supply of $X_{1}$, and Foreign has to produce the world supply of $Y_{1}$, while the world supply of $X_{2}$ and $Y_{2}$ can be produced in either country in integrated equilibrium because of identical technologies across countries in these goods.

Figure 2 is a diagrammatic representation of Proposition 1 for this case. It shows the Dixit-Norman rectangle. ${ }^{3}$ The dimensions of the box measure the world endowment of capital and labour, and the origins are for Home and Foreign. The line $\mathrm{O}_{\mathrm{H}} \mathrm{A}$ represents the resources allocated to producing the capital-intensive $\mathrm{X}$ goods, while the line $\mathrm{AO}_{\mathrm{F}}$ represents the resources allocated to producing the labour-intensive Y-goods, in the integrated equilibrium.

Given the case above, if the division of factor endowments between the two countries lies within the area $\mathrm{ABCD}$, integrated equilibrium can be replicated and hence factor price equalisation achieved through free international trade in goods alone, since we take into account the fact that Home must produce the world supply of good $X_{I}$ in which it has a technological advantage, and Foreign must

${ }^{3}$ So-called because it was first popularised by Dixit and Norman (1980). 
Figure 2. Dixit-Norman Rectangle Showing the Integrated Equilibrium in a 4-good HeckscherOhlin-Ricardo Model

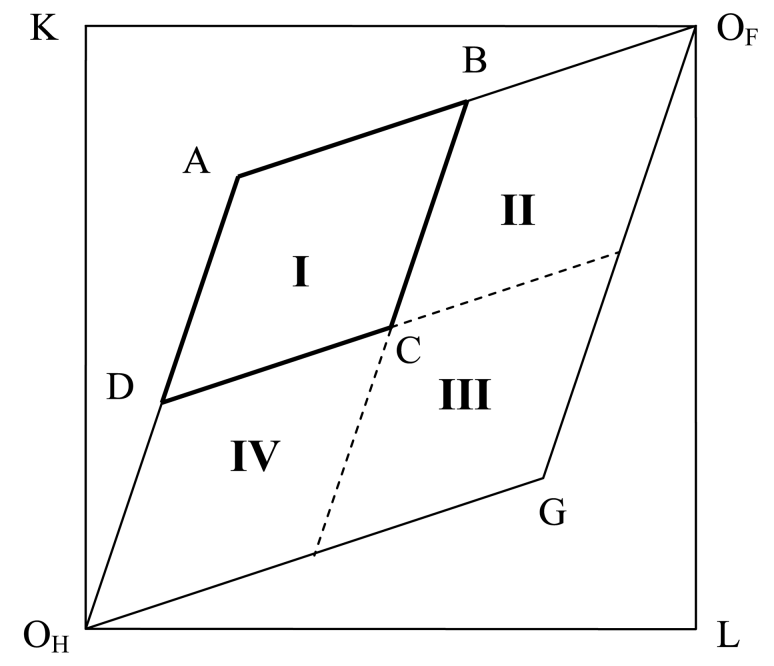

Notes: The areas I, II, III and IV indicate the areas where the integrated equilibrium can be replicated given different assumptions on technologies across countries. Region I is the integrated equilibrium when Home has a technological advantage in $X_{1}$ and Foreign in $Y_{1}$, Region II when Home has a technological advantage in both $X_{1}$ and $Y_{1}$, Region III when Home has a technological advantage in $Y_{1}$ and Foreign in $X_{1}$, and Region IV when Foreign has a technological advantage in both $X_{1}$ and $Y_{1}$.

produce the world supply of good $Y_{l}$, in which it has a technological advantage. The line $\mathrm{O}_{\mathrm{H}} \mathrm{D}$ represents the resources used in Home to produce the world supply of good $X_{l}$, while the remaining fraction DA is used by either country in producing $X_{2}$. Therefore, from Proposition 1, the ratio of the lengths of both lines is equal to the relative consumption weights on the two goods, $\frac{O_{H} D}{D A}=\frac{\alpha_{X_{1}}}{\alpha_{X}}$. Similarly, the line $\mathrm{O}_{\mathrm{F}} \mathrm{B}$ represents the resources used in Foreign to produce the world supply of good $Y_{1}$, while the remaining fraction BA is used by either country in producing $Y_{2}$. As with the $\mathrm{X}$-goods, the ratio of resources used in producing $Y_{1}$ to $Y_{2}$, is $\frac{O_{F} B}{B A}=\frac{\alpha_{Y_{1}}}{\alpha_{Y_{2}}}$.

If technologies are identical across the two countries in all industries as in the standard Heckscher-Ohlin model, then the area within which integrated equilibrium can be replicated is $\mathrm{O}_{\mathrm{H}} \mathrm{AO}_{\mathrm{F}} \mathrm{G}$, since with identical technologies, there are no constraints on the location of production of any of the goods based on technological advantage. Therefore, we have Corollary 2:

Corollary 2: The ratio of the area of the integrated equilibrium with technological 
differences across countries (Heckscher-Ohlin-Ricardo) to that with identical technologies (Heckscher-Ohlin) is equal to $\frac{\alpha_{X_{2}} \alpha_{Y_{2}}}{\left(\alpha_{X_{1}}+\alpha_{X_{2}}\right)\left(\alpha_{Y_{1}}+\alpha_{Y_{2}}\right)}$.

Corollary 2 shows that with technological differences across countries in $X_{I}$ and $Y_{1}$, the integrated equilibrium depends on the relative demands for the four goods, and it vanishes when consumers do not demand both of the technologically identical goods; that is, if $\alpha_{X_{2}}$ or $\alpha_{Y_{2}}=0$. In this case (see also Davis (1995) footnote 24), since there are fewer identical technologies (zero or one) than factors of production (two), the FPE set is of less than full dimension. Also, if consumers demand only the goods which have identical technologies across countries $\left(\alpha_{X_{1}}=\alpha_{Y_{1}}=0\right)$, then the integrated equilibrium is exactly the same as that when only technologically identical goods exist.

Consider first the second case, where consumers only demand the goods which have identical technologies across countries. This is the case of the HeckscherOhlin model; only goods with identical technologies are produced. On the other hand, consider the first case, where if we impose the stronger condition that $\alpha_{X_{2}}=\alpha_{Y_{2}}=0$, then consumers only demand the goods which are technologically differentiated across countries. This then becomes a version of the Ricardian model of trade based on relative technological differences across countries. In this case, factor price equalisation is unlikely to occur except as a coincidence. Therefore, we have the following corollary:

Corollary 3: The Heckscher-Ohlin and the Ricardian models are special cases of the HOR model, when consumers place no weight on the technologically differentiated goods, $\alpha_{X_{1}}=\alpha_{Y_{1}}=0$, and when they place no weight on the technologically identical goods, $\alpha_{X_{2}}=\alpha_{Y_{2}}=0$, respectively.

\section{Trade Patterns}

In this section we consider the pattern of trade in our four-good model. As with Davis (1995), we focus our attention on the integrated equilibrium, that is, the resource allocation that would occur if both goods and factors of production are freely traded. For concreteness, in this section assume that $\alpha_{i}=\frac{1}{4}$ for all $i$, so that the representative consumer spends an equal share of his income on each of the four goods, and therefore from Corollary 2 the integrated equilibrium is a quarter the size of the integrated equilibrium in the Heckscher-Ohlin model. ${ }^{4}$

The location of the integrated equilibrium area in the Dixit-Norman rectangle 
depends on the relative technologies between Home and Foreign. There are four possible combinations of productivities between the two countries and hence four possible locations of the integrated equilibrium - Home having a productivity advantage in both $X_{l}$ and $Y_{l}$ (in which case the integrated equilibrium is in area II in Figure 2), Foreign having a productivity advantage in both these goods (integrated equilibrium in area IV), Home having a productivity advantage in $X_{I}$ and Foreign in $Y_{l}$ (area I), and Home having a productivity advantage in $Y_{l}$ and Foreign in $X_{I}$ (area III). Areas III and IV are mirror images of areas I and II, so for expositional purposes we focus on the integrated equilibria indicated by areas I and II, as reproduced in Figure 3.

As the first step in the analysis, consider trade patterns in each of the four corners of regions I and II in Figure 3. Table 2 summarises the trade patterns in both regions. Take region I first. Here, Home has a technological advantage in $X_{I}$

Figure 3. Dixit-Norman Rectangle Showing Trade Patterns

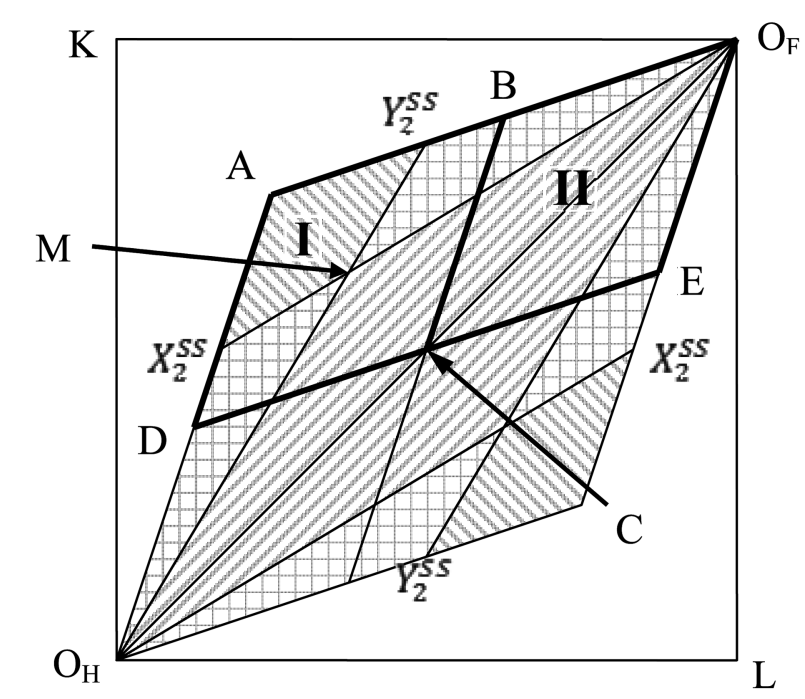

Notes: The lines $X_{2}^{S S}$ and $Y_{2}^{S S}$ are where each country is self-sufficient in $X_{2}$ and $Y_{2}$, respectively. The downward shading indicates pure inter-industry trade, where a country does not simultaneously export and import goods within the same industry group. The upward shading indicates pure intra-industry trade, where a country simultaneously exports and imports goods within both industry groups. The square shading indicates partial intra-industry trade, where a country simultaneously exports and imports goods within one industry group but not the other.

${ }^{4}$ From Corollary 2, this assumption also means that the likelihood that we get FPE in equilibrium is reduced when compared to the Heckscher-Ohlin model with identical technologies. 
Table 2. Export Patterns at Different Points of Figure 3

\begin{tabular}{cccccc}
\hline & \multicolumn{2}{c}{ Region I } & & \multicolumn{2}{c}{ Region II } \\
\cline { 2 - 3 } \cline { 5 - 6 } A & Home & Foreign & & Home & Foreign \\
B & $\mathrm{X}_{1}, \mathrm{X}_{2}$ & $\mathrm{Y}_{1}, \mathrm{Y}_{2}$ & & & \\
$\mathrm{C}$ & $\mathrm{X}_{1}, \mathrm{X}_{2}, \mathrm{Y}_{2}$ & $\mathrm{Y}_{1}$ & & $\mathrm{X}_{1}, \mathrm{X}_{2}, \mathrm{Y}_{1}$ & $\mathrm{Y}_{2}$ \\
$\mathrm{D}$ & $\mathrm{X}_{1}, \mathrm{Y}_{2}$ & $\mathrm{X}_{2}, \mathrm{Y}_{1}$ & & $\mathrm{X}_{1}, \mathrm{Y}_{1}$ & $\mathrm{X}_{2}, \mathrm{Y}_{2}$ \\
$\mathrm{E}$ & $\mathrm{X}_{1}$ & $\mathrm{Y}_{1}, \mathrm{X}_{2}, \mathrm{Y}_{2}$ & & & \\
\hline
\end{tabular}

Notes: The goods $X_{1}, X_{2}, Y_{1}$ and $Y_{2}$ indicate which goods are exported by each of Home and Foreign at each point $\mathrm{A}$ to $\mathrm{E}$ in Figure 3.

and Foreign in $Y_{1}$, so that in the integrated equilibrium, Home always exports $X_{1}$ and Foreign always exports $Y_{1}$. At point A, Home is producing the world's output of both $X_{1}$ and $X_{2}$, while Foreign is producing the world's output of both $Y_{1}$ and $Y_{2}$. Hence Home will export $X_{1}$ and $X_{2}$ in return for imports of $Y_{1}$ and $Y_{2}$ from Foreign. At point $\mathrm{B}$, Home is producing the world's output of $X_{1}, X_{2}$ and $Y_{2}$ and so exports these three goods in return for imports of $Y_{1}$ from Foreign. At point $\mathrm{C}$, Home exports $X_{1}$ and $Y_{2}$ in exchange for imports of $X_{2}$ and $Y_{l}$. Finally, at point D, Home exports $X_{1}$ in exchange for imports of $X_{2}, Y_{1}$ and $Y_{2}$.

If the integrated equilibrium is region II, then Home has a technological advantage in both $X_{1}$ and $Y_{l}$. Therefore, in the integrated equilibrium, Home always exports these two goods. At points $\mathrm{B}$ and $\mathrm{C}$ which are common to both regions I and II, the goods within each pair that each country exports depends on which country has the technological advantage, but the net factor content of trade is the same. ${ }^{5}$ Thus, at point $\mathrm{B}$, Home will export $X_{1}, Y_{1}$ and $X_{2}$ while Foreign will export $Y_{2}$. At point $\mathrm{C}$, Home exports $X_{1}$ and $Y_{1}$ in exchange for $X_{2}$ and $Y_{2}$, and at point E, Home exports $X_{1}, Y_{1}$ and $Y_{2}$ while Foreign will export $X_{2}$.

We can delineate the integrated equilibrium into smaller areas. As we move from point $\mathrm{A}$ to point $\mathrm{D}$, or from point $\mathrm{B}$ to point $\mathrm{C}$, the trade pattern changes from one where Home exports $X_{2}$ to one where Foreign exports $X_{2}$. Therefore, somewhere between these points must be a resource allocation such that both countries are self-sufficient in $X_{2}$ and hence $X_{2}$ is not traded. Given our assumptions on technology and preferences, this can be represented by a line from Foreign's origin $\mathrm{O}_{\mathrm{F}}$, denoted $X_{2}^{S S}$. Similarly, moving from point $\mathrm{C}$ to point $\mathrm{E}$ changes the trade pattern from Foreign exporting $Y_{2}$ to Home exporting $Y_{2}$. Hence

${ }^{5}$ Similarly to Helpman and Krugman (1985), the net factor content of trade can be shown by the difference between the endowment point and the consumption point, the latter of which always lies on the diagonal $\mathrm{O}_{\mathrm{H}} \mathrm{O}_{\mathrm{F}}$ since we assume identical preferences across countries. 
there is also a line defining the allocations of resources across countries such that both countries are self-sufficient in $Y_{2}$, denoted $Y_{2}^{S S}$ from Foreign's origin. A similar argument can be made for self-sufficiency lines for $X_{2}$ and $Y_{2}$ emanating from Home's origin $\mathrm{O}_{\mathrm{H}}$.

Define pure inter-industry trade as the case where each country only exports goods within one industry group, and imports those within the other industry group. Then, pure inter-industry trade occurs in the areas in the integrated equilibrium which are shaded by the downward-sloping lines, including point $\mathrm{A}$. Define also pure intra-industry trade as the case where each country is simultaneously an exporter and importer in both industry groups (albeit exporting and importing different goods within each industry). Then, pure intra-industry trade occurs in the areas shaded by the upward-sloping lines including point $C$. Finally, define partial intra-industry trade as the case where there is two-way trade in only one of the two industries. Then, partial intra-industry trade occurs in the areas shaded with squares, including points $\mathrm{B}, \mathrm{D}$ and $\mathrm{E}$.

\section{A. Trade Volume}

To facilitate analysis of the volume of trade, we divide the analysis into technologically differentiated goods $X_{1}$ and $Y_{l}$, and technologically undifferentiated goods $X_{2}$ and $Y_{2}$. Consider first the integrated equilibrium in region I. In this region, Home produces the world output of $X_{I}$ and Foreign produces the world output of $Y_{1}$. Therefore, since preferences are identical across countries and homothetic, the volume of trade in $X_{l}$ is:

$$
V T_{X_{1}}=p_{X_{1}}\left(\overline{Q_{X_{1}}}-s_{H} \overline{c_{X_{1}}}\right)=p_{X_{1}}\left(1-s_{H}\right) \overline{Q_{X_{1}}}=p_{X_{1}} s_{F} \overline{Q_{X_{1}}}
$$

while the volume of trade in $Y_{1}$ is:

$$
V T_{Y_{1}}=p_{Y_{1}}\left(\overline{Q_{Y_{1}}}-s_{F} \overline{c_{Y_{1}}}\right)=p_{Y_{1}}\left(1-s_{F}\right) \overline{Q_{Y_{1}}}=p_{Y_{1}} s_{H} \overline{Q_{Y_{1}}}
$$

where $\bar{Q}_{i}$ is the world output of good $i, \bar{C}_{i}$ is the world consumption of good $i$, and $s_{j}$ is country $j$ 's share of world income. As can be seen from both expressions, the volume of trade in $X_{I}$ within region I is increasing in Foreign's share of world income, while the volume of trade in $Y_{l}$ is increasing in Home's share of world income. Since we are assuming identical expenditure shares in each good, the total volume of trade in $X_{1}$ and $Y_{1}$ is: 


$$
V T_{X_{1}}+V T_{Y_{1}}=s_{F} p_{X_{1}} \overline{Q_{X_{1}}}+s_{H} p_{Y_{1}} \overline{Q_{Y_{1}}}=\left(s_{F}+s_{H}\right) p_{X_{1}} \overline{Q_{X_{1}}}=p_{X_{1}} \overline{Q_{X_{1}}}=p_{Y_{1}} \overline{Q_{Y_{1}}}
$$

Given endowments, technologies and preferences, the total volume of trade in $X_{l}$ and $Y_{l}$ in region $\mathrm{I}$ is a constant.

In region II, Home produces the world output of both $X_{l}$ and $Y_{l}$. Therefore, the total volume of trade in these two goods is:

$$
V T_{X_{1}}+V T_{Y_{1}}=s_{F} p_{X_{1}} \overline{Q_{X_{1}}}+s_{F} p_{Y_{1}} \overline{Q_{Y_{1}}}=2 s_{F} p_{X_{1}} \overline{Q_{X_{1}}}=2 s_{F} p_{Y_{1}} \overline{Q_{Y_{1}}}
$$

Hence, within region II, the total volume of trade in $X_{1}$ and $Y_{1}$ is increasing in Foreign's share of world income, reaching a maximum at point $\mathrm{C}$ when Foreign's share of world income is maximised at $S_{F}=\frac{1}{2}$. The level curves for this trade volume can be represented by lines that are parallel to the national income line that divides world income into Home and Foreign.

Turning now to goods $X_{2}$ and $Y_{2}$, the volume of trade in these two goods increases as one moves away from the self-sufficiency lines $X_{2}^{S S}$ and $Y_{2}^{S S}$. The level curves of the trade volume for these two goods are parallel $X_{2}^{S S}$ to and $Y_{2}^{S S}$. In region $\mathrm{I}$, given identical expenditure shares on each good, the volume of trade in these two goods at each of points A to D are:

$$
\begin{aligned}
& \text { Point A: } V T_{X_{2}}+V T_{Y_{2}}=s_{F} p_{X_{2}} \overline{Q_{X_{2}}}+s_{H} p_{Y_{2}} \overline{Q_{Y_{2}}}=p_{X_{2}} \overline{Q_{X_{2}}} \\
& \text { Point B: } V T_{X_{2}}+V T_{Y_{2}}=s_{F} p_{X_{2}} \overline{Q_{X_{2}}}+s_{F} p_{Y_{2}} \overline{Q_{Y_{2}}}=2 s_{F} p_{X_{2}} \overline{Q_{X_{2}}} \\
& \text { Point C: } V T_{X_{2}}+V T_{Y_{2}}=s_{H} p_{X_{2}} \overline{Q_{X_{2}}}+s_{F} p_{Y_{2}} \overline{Q_{Y_{2}}}=p_{X_{2}} \overline{Q_{X_{2}}} \\
& \text { Point D: } V T_{X_{2}}+V T_{Y_{2}}=s_{H} p_{X_{2}} \overline{Q_{X_{2}}}+s_{H} p_{Y_{2}} \overline{Q_{Y_{2}}}=2 s_{H} p_{X_{2}} \overline{Q_{X_{2}}}
\end{aligned}
$$

Since at point B $S_{F}<\frac{1}{2}$ and at point D $S_{H}<\frac{1}{2}$, the total volume of trade in $X_{2}$ and $Y_{2}$ in region $\mathrm{I}$ is maximised at points $\mathrm{A}$ and $\mathrm{C}$. We can perform a similar calculation for region II, giving the following results:

$$
\begin{aligned}
& \text { Point B: } V T_{X_{2}}+V T_{Y_{2}}=s_{F} p_{X_{2}} \overline{Q_{X_{2}}}+s_{H} p_{Y_{2}} \overline{Q_{Y_{2}}}=p_{X_{2}} \overline{Q_{X_{2}}} \\
& \text { Point C: } V T_{X_{2}}+V T_{Y_{2}}=s_{H} p_{X_{2}} \overline{Q_{X_{2}}}+s_{H} p_{Y_{2}} \overline{Q_{Y_{2}}}=p_{X_{2}} \overline{Q_{X_{2}}} \\
& \text { Point E: } V T_{X_{2}}+V T_{Y_{2}}=s_{H} p_{X_{2}} \overline{Q_{X_{2}}}+s_{F} p_{Y_{2}} \overline{Q_{Y_{2}}}=p_{X_{2}} \overline{Q_{X_{2}}}
\end{aligned}
$$


where the result for point $\mathrm{C}$ comes from the fact that here, $S_{H}=\frac{1}{2}$. In region II, the total volume of trade in $X_{2}$ and $Y_{2}$ is maximised at each of points $\mathrm{B}, \mathrm{C}$ and $\mathrm{E}$.

Adding the volume of trade for all four goods yields the total volume of trade. Without getting into the details of deriving the level curves of trade volumes, we can draw some general conclusions, aided by Figure 4, which is a 3-dimensional representation of the Dixit-Norman rectangle from Figure 3, with the height of the surface indicating the total trade volume in the integrated equilibrium. Depending on the structure of technology (and hence the region in which integrated equilibrium occurs), trade volume is maximised at three points in the DixitNorman rectangle: at points $\mathrm{A}, \mathrm{C}$ and $\mathrm{G}$. These are points of maximal differentiation between the two countries in terms of their production structure. This differs from Davis (1995), whose point of maximal differentiation between the two countries is at points A and G. The reason for this difference is that, because our model introduces a second Y-good that has different technologies across countries, the two countries are no longer self-sufficient in good $\mathrm{Y}$ along the diagonal of the Dixit-Norman rectangle as they are in the Davis (1995) model. Therefore, we have the following Proposition:

Proposition 4: Increasing similarity in relative factor endowments may result in increasing trade volumes.

This suggests that even small technological differences across countries may be

Figure 4. Trade Volumes in the Integrated Equilibrium

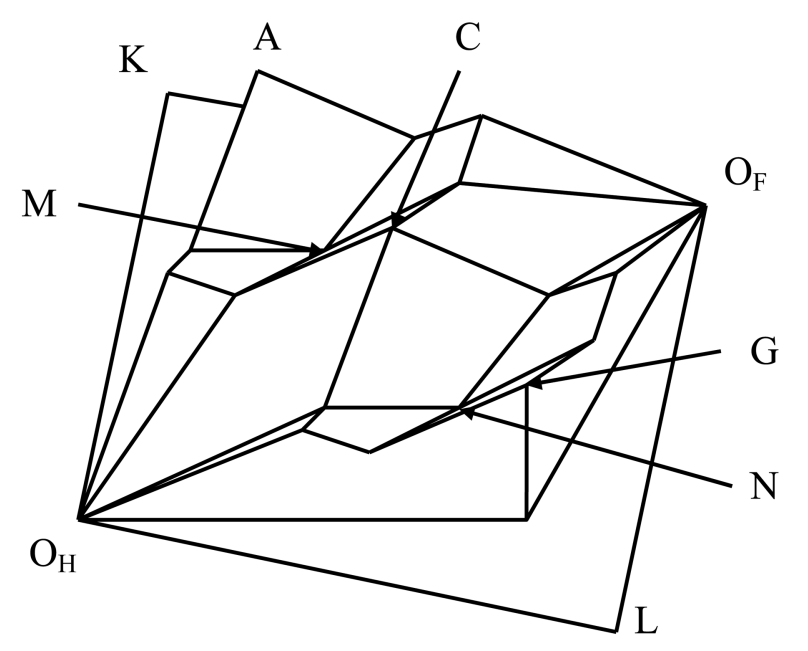

Notes: The height of the surface represents the total volume of trade given the distribution of factors of production across countries, for allocations within the integrated equilibrium. Trade volume is maximised at points $\mathrm{A}, \mathrm{C}$ and $\mathrm{G}$. 
able to account for the large volumes of trade between countries in the developed world with similar relative endowments, compared with smaller volumes of trade between developed and less developed countries, between which endowment ratios are more different. In fact, the relationship between trade volumes and relative endowments is nonlinear. In Figure 4, a movement from point A, where endowments are very different between the two countries, to point $\mathrm{C}$, where endowments are identical, implies first decreasing trade volumes, then increasing trade volumes as relative endowments become increasingly similar. Trade volume decreases from $\mathrm{A}$ to $\mathrm{M}$ as a result of decreasing inter-industry trade as countries become more similar to each other, whereas trade volume increases from $\mathrm{M}$ to $\mathrm{C}$ as a result of increasing intra-industry trade as countries become even more similar to each other. This result, that a larger share of trade is intra-industry as countries become more similar to each other, is a feature shared with many other trade models including Helpman and Krugman (1985) and Davis (1995).

\section{B. Comparison with Other Trade Models}

Compared to other standard trade models, the model proposed in this paper is able to generate increasing volumes of trade between countries that are similar in terms of their relative endowments. In this subsection we show that other standard trade models cannot generate this prediction. To facilitate the comparison, we take a cross-section of Figure 4 at the point where the two countries have identical sizes; this is the line ACG. This cross-section is shown as Figure 5a: as we move from $\mathrm{A}$ to $\mathrm{C}$ or from $\mathrm{G}$ to $\mathrm{C}$, trade volume first falls, then rises.

Figure $5 \mathrm{~b}$ gives the equivalent cross-section for the Davis (1995) HeckscherOhlin-Ricardo model with 3 goods, which is derived from Figure 5 in Davis (1995). Here, the volume of trade at first falls as countries become more similar in their relative endowments, then remains constant, so that identical countries exhibit significant trade volumes. Figure $5 \mathrm{c}$ gives the equivalent cross-section for the standard Heckscher-Ohlin model with identical technologies across countries. Here, countries that are identical in relative endowments do not trade with each other, and the trade volume increases linearly as countries become more different in their relative endowments (see Helpman and Krugman (1985) Figure 1.7).

Figures $5 \mathrm{~d}$ and $5 \mathrm{e}$ show the cross-sections for two versions of the HelpmanKrugman (1985) model of international trade with monopolistic competition. In Figure $5 \mathrm{~d}$, both the capital-intensive and labour-intensive industries are monopolistically competitive; as shown in Helpman and Krugman (1985) Figure 
Figure 5. Trade Volumes and Relative Endowments

Figure 5a: 4-good Heckscher-Ohlin-Ricardo Model

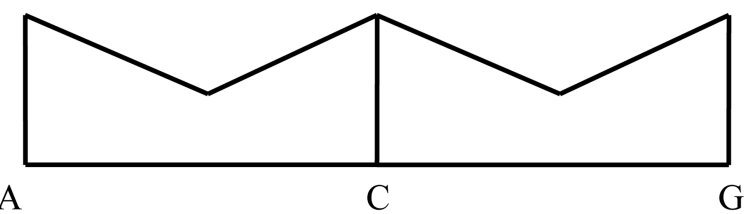

Figure 5b: 3-good Heckscher-Ohlin-Ricardo Model

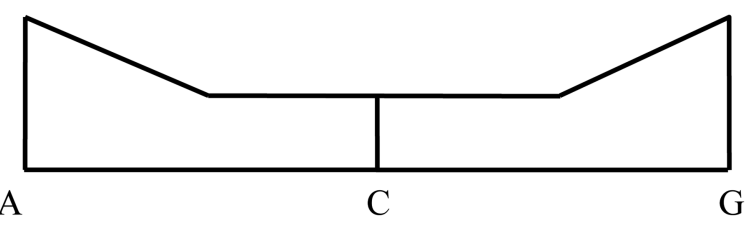

Figure 5c: Heckscher-Ohlin Model

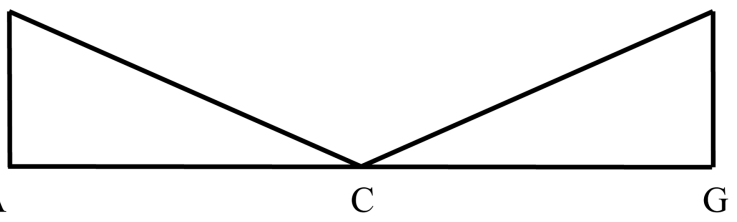

Figure 5d: Helpman-Krugman Model with IIT in Both Sectors

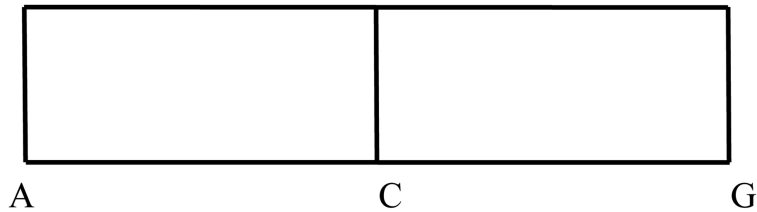

Figure 5e: Helpman-Krugman Model with IIT in Only One Sector

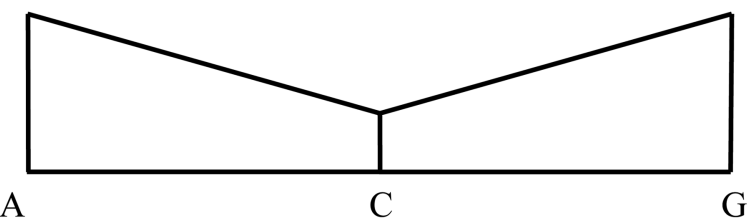

Notes: Figures 5a-5e show cross-sections of the integrated equilibrium of the Dixit-Norman rectangle for five different models, at a point where the two countries are of identical size. The height of each figure represents the volume of trade. Points A, C and G correspond to the same points in Figure 4. At point A, Home is capital-abundant relative to Foreign, whilst at point $\mathrm{G}$ the opposite is true. At point $\mathrm{C}$ the two countries are identical in their relative endowments. 
8.5, the volume of trade does not depend on relative endowments when relative country size is held constant. In Figure 5e, only one industry is monopolistically competitive, while the other industry is perfectly competitive. Here, as shown in Helpman and Krugman (1985) Figures 8.3 and 8.4, the volume of trade decreases the more similar are countries in their relative endowments, but unlike the Heckscher-Ohlin model, trade does not disappear when countries are identical to one another in their relative endowments.

Therefore, relative to the standard models of international trade, the model in this paper is the only one which is consistent with the nonlinear relationship between relative endowments and trade volumes as documented in section II. The model is also consistent with the nonlinear relationship between relative country sizes and trade volumes. Returning to Figure 4, it can be seen that trade volume is reduced along the two countries' self-sufficiency curves in $X_{2}$ and $Y_{2}$ compared with the surrounding area. Results from Soo (2008) indicate that holding relative endowment ratios constant, a change in relative country sizes represents a movement along a curve. Since our regressions in section II do control for relative endowments, a change in relative country sizes represents a movement along a curve which may intersect the self-sufficiency lines. Such an intersection would imply that as countries become more similar in their relative sizes, trade volumes will first decrease, then increase, hence generating a U-shaped relationship between trade volumes and country sizes.

\section{Conclusions}

How can we account for the large volumes of trade that are observed between countries that are relatively similar to each other in terms of their factor endowments? This paper develops a model that can explain such large trade volumes between similar countries. The model is based on Ricardian technological differences and factor endowment differences across countries in a perfectly competitive framework. In the model, as countries become more similar to one another in terms of their relative endowments, they may become more specialised because of these technological differences, so that the volume of trade increases. This prediction of possibly increasing trade volumes as countries become more similar in their relative endowments is shown to be consistent with the empirical evidence, and cannot be explained by other conventional trade models.

In developing the model, we make use of the analytical tool of the integrated 
equilibrium. We show that the size of the integrated equilibrium and hence the likelihood of factor price equalisation in the model depends on consumer demand. A greater weight placed by consumers on goods which are technologically differentiated relative to goods which have identical technologies across countries, places a tighter constraint on the production structure of the world economy, and hence reduces the size of the integrated equilibrium. We use this to show how varying the coefficients on the Cobb-Douglas utility function allows us to obtain the Heckscher-Ohlin and the Ricardian models as special cases of the more general Heckscher-Ohlin-Ricardo model.

\section{Acknowledgements}

Thanks to an anonymous referee, Donald Davis, Gilles Duranton, Steve Redding, and seminar participants at Lancaster, Nottingham, and the European Trade Study Group in Vienna for helpful comments on an earlier draft. The author is responsible for any errors and omissions.

Received 1 April 2009, Revised 24 August 2009, Accepted 27 August 2009

\section{References}

Anderson, J. E. (1979), “A Theoretical Foundation for the Gravity Equation”, American Economic Review, 69(1), pp. 106-116.

Arellano, M. and S. Bond (1991), "Some Tests of Specification for Panel Data: Monte Carlo Evidence and an Application to Employment Equations", Review of Economic Studies, 58(2), pp. 277-297.

Balboni, A. (2006), "Cross-Country Technological Differences as a Determinant of Vertical Intra-Industry Trade: a Theoretical Model”, Economie Internationale, 106, pp. 25-55.

Baum, C. F., M. E. Schaffer and S. Stillman (2007), "Enhanced Routines for Instrumental Variables/GMM Estimation and Testing", Stata Journal, 7(4), pp. 465-506.

Chung, C. (2003), "Factor Content of Trade: Nonhomothetic Preferences and "Missing Trade", Mimeo, Georgia Institute of Technology.

Davis, D. R. (1995), "Intra-industry Trade: a Heckscher-Ohlin-Ricardo Approach", Journal of International Economics, 39(3-4), pp. 201-226.

Davis, D. R. (1997), "Critical Evidence on Comparative Advantage? North-North Trade in a Multilateral World", Journal of Political Economy, 105(5), p. 1051-1060.

Dixit, A. K. and V. Norman (1980), Theory of International Trade, Cambridge, 
Cambridge University Press.

Flam, H. and E. Helpman (1987), "Vertical Product Differentiation and North-South Trade", American Economic Review, 77(5), pp. 810-822.

Fujita, M., P. R. Krugman and A. J. Venables. (1999), The Spatial Economy, Cambridge, MA, MIT Press.

Harrigan, J. (1997), "Technology, Factor Supplies and International Specialization:

Estimating the Neoclassical Model", American Economic Review, 87(4), pp. 475494.

Helpman, E. and P. R. Krugman (1985), Market Structure and Foreign Trade, Cambridge, MA, MIT Press.

Heston, A., R. Summers and B. Aten (2006), "Penn World Table Version 6.2", Center for International Comparisons of Production, Income and Prices, University of Pennsylvania.

Linder, S. B. (1961), An Essay on Trade and Transformation, New York, Wiley.

Markusen, J. R. (1986), "Explaining the Volume of Trade: an Eclectic Approach", American Economic Review, 76(5), pp. 1002-1011.

Matsuyama, K. (2000), “A Ricardian Model with a Continuum of Goods under Nonhomothetic Preferences: Demand Complementarities, Income Distribution, and North-South Trade", Journal of Political Economy, 108(6), pp. 1093-1120.

Mitra, D. and V. Trindade (2005), "Inequality and Trade", Canadian Journal of Economics, 38(4), pp. 1253-1271.

Ramezzana, P. (2000), "Per Capita Income, Demand for Variety, and International Trade: Linder Reconsidered", Centre for Economic Performance Discussion Paper No. 460.

Roodman, D. (2009), "How to Do Xtabond2: an Introduction to Difference and System GMM in Stata", Stata Journal, 9(1), pp. 86-136.

Soo, K. T. (2008), "Trade Volume and Country Size in the Heckscher-Ohlin Model", Economics Bulletin, 6(1), p. 1-7.

Stokey, N. L. (1991), "The Volume and Composition of Trade between Rich and Poor Countries", Review of Economic Studies, 58(1), pp. 63-80. 